\title{
CORRIGENDUM
}

\section{Intra-national variation in trends in overweight and leisure time physical activities in The Netherlands since 1980: stratification according to sex, age and urbanisation degree}

\author{
GCM Gast, FJM Frenken, LATM van Leest, GCW Wendel-Vos and WJE Bemelmans \\ International Journal of Obesity (2007) 31, 566. doi:10.1038/sj.ijo.0803468; published online 12 September 2006
}

Correction to: International Journal of Obesity (2007) 31, 515-520. doi: 10.1038/sj.ijo.0803429

Since the publication of the above paper the authors have noticed several errors.

The author name GCM Gast was published incorrectly in the above-referenced paper. The correct author list is shown above.

The following sentence was missed out in the original manuscript and is to be included on p 5 after the sentence: A study of Williamson et al. ${ }^{33}$ found that, after controlling for ageing, nulliparous women gained less in weight compared to women with having one, two or three live births.

Since, according to Statistics Netherlands, the absolute number of children has increased during 1980 and 2004, this may have contributed to the relatively large changes in BMI among younger women.

Figure 4 was incorrectly published in the above referenced paper. The correct figure is shown here.

The authors would like to apologise for these errors.
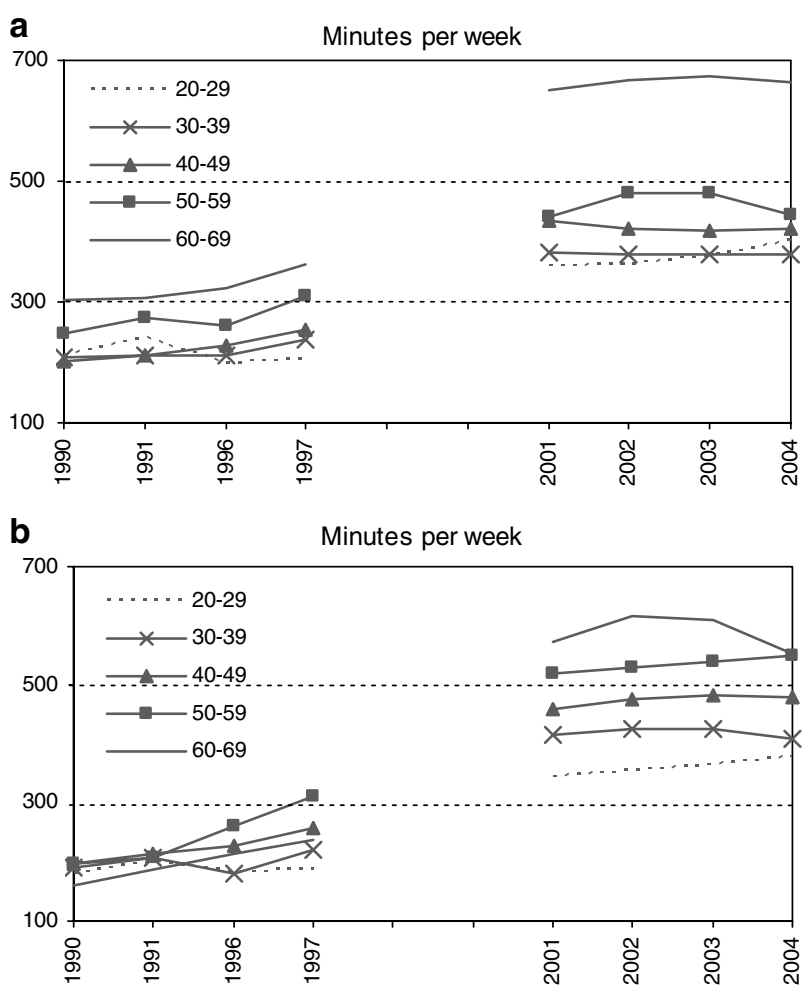

Figure 4 Mean minutes per week spent on leisure time physical activities during the periods 1990-1997 and 2001-2004 in (a) men and (b) women by age groups. (CBS) Because of modification in questioning, the two periods of 1990-1997 and 2001-2004 are not comparable. 